\title{
ある種のセクタ条件に基づいた離散時間非線形 フィードバック系の大局的漸近安定性
}

\author{
武藤 康 彦*・市川邦彦* \\ Globally Asymptotic Stability of Discrete Nonlinear Feedback \\ Systems Based on a Certain Kind of a Sector Condition \\ Yasuhiko MútoH* and Kunihiko IchIKAwA*
}

\begin{abstract}
In this paper, it is shown that Kalman's conjecture is valid for discrete nonlinear feedback system if Hurwitz sector is replaced by more restricted sector that is called ESF-gain sector. Many of practical nonlinearities are included in this class. It is also shown that ESF-gain sector which depends on the solution of Lyapunov's matrix equation can be derived by solving a quadratic equation.
\end{abstract}

Key Words: nonlinear feedback system, stability of nonlinear system sector condition

\section{1. 緒言}

本論文では，ある種のゼロメモリー型非線形要素を フィードバック回路にもつ離散時間非線形フィードバ ック系の大局的漸近安定性について考察を行う.

一般に Kalman の推測と呼ばれる連続時間非線形つ ィードバック系の安定性に関する考察がある ${ }^{1 !}$ 。乙れ は Hurwitz セク夕(後出)により規定されるある条件 を，非線形要素が満たせばての系は大局的漸近安定と なるであろうというものである．乙れには多くの実際 的な非線形性が含まれ，また非常に使いやすい形をし ているが，ての推測には反例が存在し正しくないこと がわかっている2゙.

本論文では，離散系においててのセクタ条件にある 制約を加えるととで, 大局的漸近安定性が保証された 非線形フィードバック系が構成できるととを示す。実 際のシステムが大局的漸近安定であるかどうかはこの 制約されたセクタの大きさを実際に求めることにより

* 上智大学理工学部 東京都干代田区紀尾井町 7-1

* Faculty of Science and Technology, Sophia University, Chiyoda-ku, Tokyo (Received May 28, 1990) (Revised September 13, 1990)
一つの十分条件として直接判定することができる.

以下，第 2 章において制限されたセク夕条件に基づ き, 非線形フィードバック系の大局的漸近安定性を縮 小写像の原理を利用して述べる.さらに，3章におい て制限されたセクタが, リアプノフの行列方程式の解 を利用した 2 次方程式の根により直接求められること を示す. 4 章では簡単な例題を挙げる.

\section{2. 非線形フィードバック系の 大局的漸近安定性}

次式で示される一入力一出力非線形フィードバック 系を考えよう (Fig. 1).

[線形部分]

$$
\begin{aligned}
& \boldsymbol{x}(t+1)=A \boldsymbol{x}(t)+\boldsymbol{b} u(t) \\
& y(t)=\boldsymbol{c}^{T} \boldsymbol{x}(t)
\end{aligned}
$$

[非線形部分]

$$
u(t)=-f(y(t))
$$

ここで $\boldsymbol{x}(t), \boldsymbol{b}, \boldsymbol{c} \in R^{n}, y(t), u(t) \in R^{1}, A \in R^{n \times n}$ で あるあのとする。 な抢以下で用いるノルムは，ベクト ルに関しては通常のユークリッドノルム, また行列に 関してはユークリッドノルムから導かれたノルム，す なわち

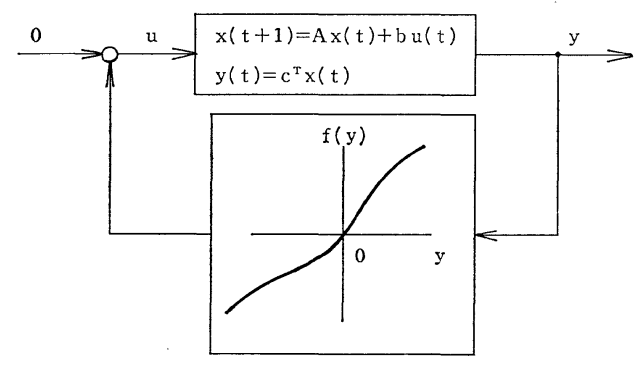

Fig. 1 Nonlinear feedback system 


$$
\|A\|=\left[\lambda_{\max }\left(A^{T} A\right)\right]^{1 / 2}
$$

$\lambda_{\max }(・)$ は行列の最大固有值とする.

議論に入る前に，いくつかの用語の定義を行ってお $<$.

【定義 1】 Fig. 2 に示すように, $f(y)=k_{L} y$ と $f(y)=k_{U} y$ に挟まれた領域をセクタ $\left[k_{L}, k_{U}\right]$ という $\left(k_{L}<k_{U}\right)$. ただし領域は直線 $f(y)=k_{L} y$ から反時計 回りの方向にとるむのとする.

【定義 2】 $k \in\left[k_{L}, k_{U}\right]$ なるすべてのkについて $A-\boldsymbol{b}^{T} k$ が漸近安定となるようなセクタ $\left[k_{L}, k_{U}\right]$ を システム (2.1)の Hurwitz セクタと呼ぶ.

【定義 $3 】$ ある正定対称行列 $P \in R^{n \times n}$ 亿対して,

$$
\left(A-\boldsymbol{b}^{T} k\right)^{T} P\left(A-\boldsymbol{b} \boldsymbol{c}^{T} k\right)-P<0
$$

となるようなすべての実数 $k$ の集合を $S(P)$ とおいて， これを等価的安定化フィードバックゲインの集合と呼 ぶ. 簡単のためとこでは ESF-ゲイン (Equivalently Stabilizing Feedback gain) と呼ぶことにする.

$$
\begin{aligned}
\text { システム } & \\
& \boldsymbol{x}(t+1)=\left(A-\boldsymbol{b} \boldsymbol{c}^{T} k\right) \boldsymbol{x}(t)
\end{aligned}
$$

を考えたとき, $x(t)^{T} P x(t)$ はすべての $k \in S(P)$ に対 してリアプノフ関数になっている.

【定義 $4 】$ ある $k_{L}<k_{U}$ に対して $\left[k_{L}, k_{U}\right]$ が $\mathrm{ESF}$ ゲインの集合になっているとき，七クタ $\left[k_{L}, k_{U}\right]$ を $\mathrm{ESF}$-ゲインセクタと呼ぶ.

明らかにシステム (2.1) に対して, ESF-ゲインセク タは Hurwitz セクタに含まれる.

さて，非線形フィードバック系(2.1)，(2.2)に括い て非線形要素 $f(y)$ が以下の条件を満たしているもの とする.

(1) $f(y)$ は連続で区分的になめらかな関数で $f(0)=0$

(2) $f(y)$ の微分可能な点において

$$
k_{L} \leqq \frac{d f}{d y} \leqq k_{U}
$$

(3) セクタ $\left[k_{L}, k_{U}\right]$ は ESF-ゲインセクタであ る.

このような非線形関数 $f(y)$ は，明らかに ESF-ゲイ

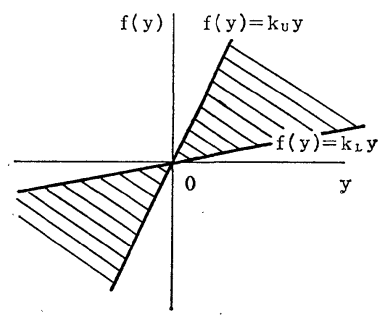

Fig. 2 Sector $\left[k_{L}, k_{U}\right]$
ンセクタ $\left[k_{L}, k_{U}\right]$ 内にある. Fig. 3 に上の条件を満 たす $f(y)$ の例をいくつか示す.

いま，(2.3)式を満たす正定対称行列 $P$ を

$$
P=T^{T} T \quad T \in R^{n \times n} \text { (正則) }
$$

と表示すると,

$$
\begin{aligned}
& A^{*}=T A T^{-1} \\
& \boldsymbol{b}^{*}=T \boldsymbol{b} \\
& \boldsymbol{c}^{* T}=\boldsymbol{c}^{T} T^{-1}
\end{aligned}
$$

なる正則変換により

$$
\left(A^{*}-\boldsymbol{b}^{*} \boldsymbol{c}^{* T} k\right)^{T}\left(A^{*}-\boldsymbol{b}^{*} \boldsymbol{c}^{* T} k\right)<I
$$

が成立する. との式は

$$
\left\|A^{*}-\boldsymbol{b}^{*} \boldsymbol{c}^{* T} k\right\|<1 \quad \forall k \in S(P)
$$

を意味している.

さて，非線形フィードバック系 (2.1)，(2.2)におい て非線形要素 $f(y)$ が条件 $(1) \sim(3)$ を満たしている あのとする．いま， $k_{L} ， k_{U}$ により決まるセクタ $\left[k_{L}\right.$, $\left.k_{U}\right]$ が $\mathrm{ESF}$-ゲインセクタであるとすると，上述した ように(2.6)式に示す正則行列 $T$ により

$$
\boldsymbol{w}(t)=T \boldsymbol{x}(t) \quad \boldsymbol{w}(t) \in R^{n}
$$

と正則変換を行うことで (2.1)，(2.2)式はつぎのよう に表わすととができる.

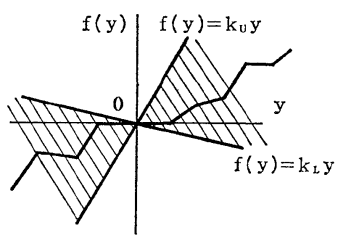

(a) Continuous broken line function

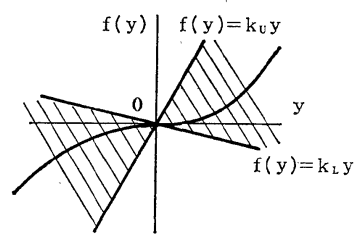

(b) Continuous and smooth function

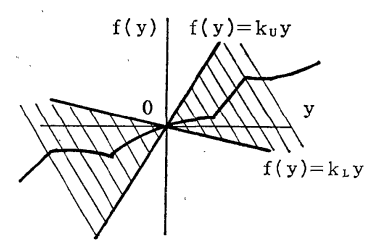

(c) Continuous and piecewise smooth function

Fig. 3 Nonlinearities which satisfy the conditions (1), (2) and (3) 
1581991 年 2 月

$$
\begin{aligned}
& \boldsymbol{w}(t+1)=F(\boldsymbol{w}(t)) \\
& F(\boldsymbol{w}(t))=A^{*} \boldsymbol{w}(t)-\boldsymbol{b}^{*} f\left(\boldsymbol{c}^{* T} \boldsymbol{w}(t)\right)
\end{aligned}
$$

ただし， $A^{*}, \boldsymbol{b}^{*}, \boldsymbol{c}^{*}$ は (2.7) 式により与えられる. 乙 のとき $\boldsymbol{w}_{1}, \boldsymbol{w}_{2}$ を $R^{n}$ 中の任意の 2 点とすると次式が 成立する.

(Case 1) $\boldsymbol{c}^{* T} \boldsymbol{w}_{1} \neq \boldsymbol{c}^{* T} \boldsymbol{w}_{2}$ のとき $f(y)$ が条件 $(1)$ ( 3$)$ を満たすととからある $k \in$ $\left[k_{L}, k_{U}\right]$ に対して

$$
f\left(\boldsymbol{c}^{* T} \boldsymbol{w}_{2}\right)=f\left(\boldsymbol{c}^{* T} \boldsymbol{w}_{1}\right)+k\left(\boldsymbol{c}^{* T} \boldsymbol{w}_{2}-\boldsymbol{c}^{* T} \boldsymbol{w}_{1}\right)
$$

が成立する，てれを用いて次式を得る。

$$
\begin{aligned}
& \left\|F\left(\boldsymbol{w}_{2}\right)-F\left(\boldsymbol{w}_{1}\right)\right\| \\
& \quad=\left\|A^{*} \boldsymbol{w}_{2}-\boldsymbol{b}^{*} f\left(\boldsymbol{c}^{* T} \boldsymbol{w}_{2}\right)-A^{*} \boldsymbol{w}_{1}+\boldsymbol{b}^{*} f\left(\boldsymbol{c}^{* T} \boldsymbol{w}_{1}\right)\right\| \\
& \quad=\left\|\left(A^{*}-k \boldsymbol{b}^{*} \boldsymbol{c}^{* T}\right)\left(\boldsymbol{w}_{2}-\boldsymbol{w}_{1}\right)\right\| \\
& \quad \leqq\left\|A^{*}-k \boldsymbol{b}^{*} \boldsymbol{c}^{* T}\right\| \cdot\left\|\boldsymbol{w}_{2}-\boldsymbol{w}_{1}\right\| \\
& \quad<\rho_{1} \cdot\left\|\boldsymbol{w}_{2}-\boldsymbol{w}_{1}\right\|, \quad 0<\rho_{1}<1
\end{aligned}
$$

(Case 2) $\boldsymbol{c}^{* T} \boldsymbol{w}_{1}=\boldsymbol{c}^{* T} \boldsymbol{w}_{2}$ のとき

条件 (1), (2)より, ある $k \in\left[k_{L}, k_{U}\right]$ に対して次式 加成立する。

$$
f\left(\boldsymbol{c}^{* T} \boldsymbol{w}_{1}\right)=k \boldsymbol{c}^{* T} \boldsymbol{w}_{1}=k \boldsymbol{c}^{* T} \boldsymbol{w}_{2}=f\left(\boldsymbol{c}^{* T} \boldsymbol{w}_{2}\right)
$$

したがって, 次式を得る.

$$
\begin{aligned}
& \left\|F\left(\boldsymbol{w}_{2}\right)-F\left(\boldsymbol{w}_{1}\right)\right\| \\
& \quad=\left\|A^{*} \boldsymbol{w}_{2}-\boldsymbol{b}^{*} f\left(\boldsymbol{c}^{* T} \boldsymbol{w}_{2}\right)-A^{*} \boldsymbol{w}_{1}+\boldsymbol{b}^{*} f\left(\boldsymbol{c}^{* T} \boldsymbol{w}_{1}\right)\right\| \\
& \quad=\left\|\left(A^{*}-k \boldsymbol{b}^{*} \boldsymbol{c}^{* T}\right)\left(\boldsymbol{w}_{2}-\boldsymbol{w}_{1}\right)\right\| \\
& \quad \leqq\left\|A^{*}-k \boldsymbol{b}^{*} \boldsymbol{c}^{* T}\right\| \cdot\left\|\boldsymbol{w}_{2}-\boldsymbol{w}_{1}\right\| \\
& \quad<\rho_{2} \cdot\left\|\boldsymbol{w}_{2}-\boldsymbol{w}_{1}\right\|, \quad 0<\rho_{2}<1
\end{aligned}
$$

(2.14)，(2.16)式より次式が成立する.

$$
\begin{gathered}
\left\|F\left(\boldsymbol{w}_{1}\right)-F\left(\boldsymbol{w}_{2}\right)\right\|=\rho \cdot\left\|\boldsymbol{w}_{1}-\boldsymbol{w}_{2}\right\|, \quad 0<\rho<1 \\
{ }^{\forall} \boldsymbol{w}_{1}, \boldsymbol{w}_{2} \in R^{n} .
\end{gathered}
$$

したがって， $F$ は縮小写像となり $R^{n}$ 内の任意の初期 点 $\boldsymbol{w}_{0}$ から出発して, $\boldsymbol{w}_{i+1}=F\left(\boldsymbol{w}_{i}\right)$ により定まる点列 $\left\{\boldsymbol{w}_{0}, \boldsymbol{w}_{1}, \boldsymbol{w}_{2}, \cdots\right\}$ は $F$ の不動点すなわち $R^{n}$ の原点に 収束する ${ }^{3)}$ ，とのととは (2.1)，（2.2)の非線形フィー ドバック系が大局的漸近安定であるととを意味してい る.すなわちつぎの定理が得られた。

《定理 1》 非線形フィードバック系(2.1)，(2.2)に おいて, 非線形要素 $f(y)$ が条件 $(1)$ ( 3$)$ を満たせ ば，この系の原点は大局的漸近安定である.

定理中，条件（3)の ESF-ゲインセクタをHurwitz セクタで置き換えれば，乙れは Kalman の推測を離散 系に対して適用したものとみなせる．すなわち，定理 1 は“離散系における Kalman の推測”においてセ クタを ESF-ゲインセクタにまで狭めれば，大局的漸 近安定性は常に保証されるととを述べている.
第 27 巻 第 2 号

\section{ESF-ゲインセクタの導出}

定理 1 を実際のシステムに適用しようとするとき, 当然，ESF-ゲインセクタを求めることが要求される。 以下では，線形部分のシステムが与えられたとき，そ の ESF-ゲインセクタの大きさを求める一つの方法に ついて述べる．乙こでは一般性を失うことなく $A$ を漸 近安定行列と仮定する. あし $A$ が不安定行列であった 場合, $A-\boldsymbol{b}^{T} k_{1}$ が漸近安定となるようなある $k_{1}$ を 選んで，そこから出発して同じ手順により $A$ に対する ESF-ゲインセクタを求めることができるからである (このような $k_{1}$ が存在しなければ安定化できない).

いま，Aが漸近安定行列としたととから，任意の正 定対称行列 $Q$ をえたときつぎのリアプノフの行列方 程式を満たす正定対称行列 $P$ が一意に定まる。

$$
A^{T} P A-P=-Q
$$

求めるべきものは

$$
-\left(A-\boldsymbol{b c}^{T} k\right)^{T} P\left(A-\boldsymbol{b c}^{T} k\right)+P>0
$$

となるような $k$ の範囲である. こてで, $A, \boldsymbol{b}, \boldsymbol{c}$ は可 観測正準形，すなわち

$$
\begin{aligned}
A & =\left[\begin{array}{cc}
0 & \vdots \\
\cdots \ldots \ldots & \ldots \\
I_{n-1} & \vdots
\end{array}\right], \quad \boldsymbol{a} \in R^{n} \\
\boldsymbol{c}^{T} & =[0, \cdots, 0,1]
\end{aligned}
$$

なる形をしているものとする，一方，(3.1)式におけ る正定対称行列 $P$ はつきのように部分行列により表示 することができる。

$$
\begin{aligned}
P & =\left[\begin{array}{c}
* \cdots * \\
\cdots \cdots \cdots \\
P_{2}
\end{array}\right]=\left[\begin{array}{cc}
* & \vdots \\
\vdots & \vdots \\
* & P_{2}^{T}
\end{array}\right] \\
& =\left[\begin{array}{ccc}
P_{n-1}^{(1)} & \vdots & \boldsymbol{p}_{n-1} \\
\hdashline \cdots \cdots \cdots & \cdots \cdots \cdots \cdots \\
\hdashline p_{n-1}^{T} & \vdots & p_{n n}
\end{array}\right]=\left[\begin{array}{ccc}
* & * \cdots * * \\
\cdots & \cdots \cdots \cdots \cdots \\
* & \vdots & \\
\vdots & P_{n-1}^{(2)}
\end{array}\right]
\end{aligned}
$$

ただし， $P_{2} \in R^{(n-1) \times n}, P_{n-1}^{(1)}, P_{n-1}^{(2)} \in R^{(n-1) \times(n-1)}, \boldsymbol{p}_{n-1}$ $\in R^{n-1}, P_{n n} \in R^{1}$ である. (3.3)，(3.4)式を用いて (3.2)式の左辺を計算して次式を得る.

$$
\begin{aligned}
& -\left(\left(A-\boldsymbol{b} \boldsymbol{c}^{T} k\right)^{T} P\left(A-\boldsymbol{b} \boldsymbol{c}^{T} k\right)-P\right)=
\end{aligned}
$$

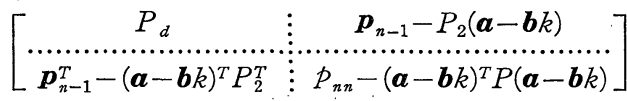

ここで $P_{d}\left(\in R^{(n-1) \times(n-1)}\right)$ は次式で定義される.

$$
P_{d}=P_{n-1}^{(1)}-P_{n-1}^{(2)}
$$

(3.5)式の右辺は $k=0$ のとき明らが正定対称行列で あるので，行列 $P_{d}$ あ正定対称である. したがって求 めるべき $k$ の範囲は (3.5)式の右辺の行列の行列式が 正となるような $k$ の範囲である. この行列式の值はつ ぎのように計算される. 
det

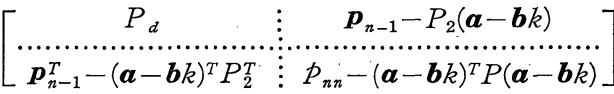

$$
\begin{aligned}
& =\left(\operatorname{det} P_{d}\right) \cdot\left[p_{n n}-(\boldsymbol{a}-\boldsymbol{b} k)^{T} P(\boldsymbol{a}-\boldsymbol{b} k)\right. \\
& \left.-\left\{\boldsymbol{p}_{n-1}-P_{2}(\boldsymbol{a}-\boldsymbol{b} k)\right\}^{T} P_{d}^{-1}\left\{\boldsymbol{p}_{n-1}-P_{2}(\boldsymbol{a}-\boldsymbol{b} k)\right\}\right] \\
& =\left(\operatorname{det} P_{d}\right) \cdot\left\{d_{2} k^{2}+d_{1} k+d_{0}\right\}
\end{aligned}
$$
ただし，

$$
\begin{aligned}
d_{2}= & -\boldsymbol{b}^{T}\left(P+P_{2}^{T} P_{d}^{-1} P_{2}\right) \boldsymbol{b} \\
d_{1}= & 2\left\{\boldsymbol{a}^{T}\left(P+P_{2}^{T} P_{d}^{-1} P_{2}\right) \boldsymbol{b}-\boldsymbol{b}^{T} P_{2}^{T} P_{d}^{-1} \boldsymbol{p}_{n-1}\right\} \\
d_{0}= & P_{n n}-\boldsymbol{a}^{T}\left(P+P_{2}^{T} P_{d}^{-1} P_{2}\right) \boldsymbol{a} \\
& -\boldsymbol{p}_{n-1}^{T} P_{d}^{-1} \boldsymbol{p}_{n-1}+2 \boldsymbol{a}^{T} P_{2}^{T} P_{d}^{-1} \boldsymbol{p}_{n-1}
\end{aligned}
$$

したがって, $\operatorname{det} P_{d}>0$ より, 求めるべき $k$ の範囲は

$$
d_{2} k^{2}+d_{1} k+d_{0}>0
$$

なる領域である. $k=0$ のとき(3.7)式は正であるとと より $d_{0}>0$ である. これと $\dot{d}_{2}<0$ とから (3.9)式は常 に二つの異なる実根をむつ。乙れより

$$
d_{2} k^{2}+d_{1} k+d_{0}=0
$$

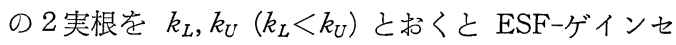
クタはセクタ $\left[k_{L}, k_{U}\right]$ で与えられる.

ただし，乙てに得られた ESF-ゲインセクタは，P， すなわちQの選び方に依存しており，なるべく大きな ESF-ゲインセクタを確保するためには，Qを適当に 変化させて，対応する ESF-ゲインセクタを何回か 求めるととが必要となる．乙のようにして求まった ESF-ゲインセクタに関して非線形要素 $f(y)$ が条件 (1)〜 (3)を満たしていれば, そのような非線形フィ 一ドバック系の原点の大局的漸近安定性は常に保証さ れる. むちろん, 最大の ESF-ゲインセクタが得られ てはいないので, ててで得られた ESF-ゲインセクタ 外でも不安定となるとは限らない。

\section{4. 例 題}

〔例題1〕次式で示されるプラントを考える.

$$
G(z)=\frac{1}{z^{2}-0.3 z+0.4}
$$

対応する可観測正準形の実現はつぎのとおりである.

$$
\begin{aligned}
& A=\left[\begin{array}{lr}
0 & 0.4 \\
1 & -0.3
\end{array}\right] \\
& \boldsymbol{b}=\left[\begin{array}{l}
1 \\
0
\end{array}\right] \\
& \boldsymbol{c}^{T}=[0,1]
\end{aligned}
$$

このプラントの Hurwitz セクタはセクタ $[-0.3$, 1.4]となる. 以下に，Aに対するリアプノフの行列 方程式に扔いて， 3 種の正定対称行列 $Q$ を与えたとき の ESF-ゲインセクタを計算してみよう. 三つの場合 についてQとそのときのリアプノフの行列方程式の解

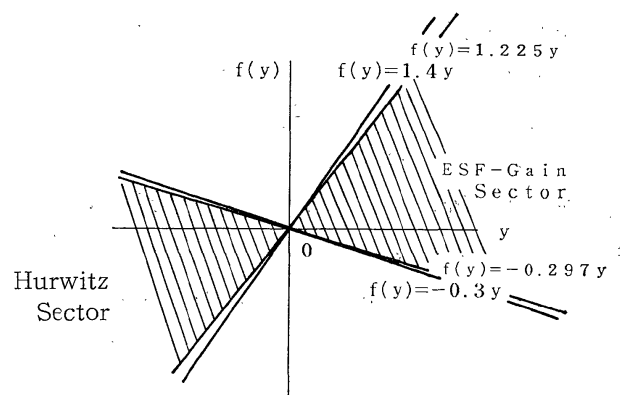

Fig. 4 Hurwitz sector and one of EFS-gain sectors (Example 1)

$P$ ，そしてそのPに対応した ESF-ゲインセクタを挙 げておく.

(1)

$$
Q=\left[\begin{array}{ll}
1 & 0 \\
0 & 1
\end{array}\right], \quad P=\left[\begin{array}{rr}
2.841 & -0.921 \\
-0.921 & 1.841
\end{array}\right]
$$

ESF-ゲインセクタ : $\left[k_{L}, k_{U}\right]=[-0.263,1.029]$

(2)

$$
Q=\left[\begin{array}{ll}
2 & 1 \\
1 & 3
\end{array}\right], \quad P=\left[\begin{array}{rr}
6.635 & -0.651 \\
-0.651 & 4.635
\end{array}\right]
$$

$\mathrm{ESF}$ ゲインセクタ : $\left[k_{L}, k_{U}\right]=[-0.297,1.225]$

(3)

$$
Q=\left[\begin{array}{ll}
5 & 2 \\
2 & 1
\end{array}\right], \quad P=\left[\begin{array}{ll}
6.587 & 2.540 \\
2.540 & 1.587
\end{array}\right]
$$

ESF-ゲインセクタ : $\left[k_{L}, k_{U}\right]=[-0.084,0.301]$ 以上の三つのなかでは, (2)によって得られたセクタ [-0.297, 1.225]が最大であり，乙れを ESF-ゲイン セクタとして利用するてとができる. Fig. 4 亿，乙 のプラントに対する Hurwitz セクタと ESF-ゲイン セクタを示しておく．ての ESF-ゲインセクタに対し て条件 (1)〜 (3)を満たす非線形要素をむつ非線形つ ィードバック系は大局的漸近安定となる. ての例題で は Hurwitz セクタと ESF-ゲインセクタとは実質的 に差はないといえる.

\section{5. 結言}

本論文では離散時間非線形フィードバック系におい て，Hurwitz セクタを ESF-ゲインセクタにまで制 限すれば，離散系における Kalman の推測というべき あのが成立するととを示した. Kalman の推測自身は 直感的でわかりやすく，工学的にも意味のある多くの 非線形性を含んでいるので; 求まる ESF-ゲインセク タが広ければ, 乙の安定解析はかなり利用価值の高い

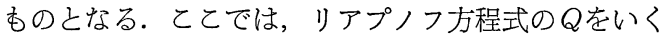
つか与えたとき,対応する ESF-ゲインセクタを求め, 
そのうち最も広いセクタを ESF-ゲインセクタとし た．しかし，最大の ESF-ゲインセクタを求めるとと は末解決であり, その広さと Hurwitz セクタの広さ との関係も含めて, 今後の課題としたい.

また，本論文では離散系のみを対象亡したが，それ は縮小写像の原理之逐次近似法の原理が離散系特有の 応答に対して容易に適用できることによる。したがっ て，てこで行った議論をそのまま直ちに連続系に対し て適用するととはできない。
参 考 文 献

1) R. E. Kalman: Physical and Mathematical Mechanisms of Instability in Nonlinear Automatic Control Systems, Trans. ASME, 79-3, 553/556 (1957)

2) R. E. Fitts: Two Counter Examples to Aizerman's Conjecture, IEEE Trans. Automatic Control, AC11-3, 553/556 (1966)

3）コルモゴロフ，フォーミン：函数解析の基礎（上), 岩波 書店 (1979) 